\title{
Programmed cell death 4 overexpression enhances sensitivity to cisplatin via the JNK/c-Jun signaling pathway in bladder cancer
}

\author{
JUNLI LIU ${ }^{1}$, RUIRUI ZHAI ${ }^{2}$, JINGJIE ZHAO ${ }^{1}$, FENG KONG $^{3}$, JUE WANG ${ }^{3}$, \\ WEN JIANG ${ }^{3}$, QIAN XIN ${ }^{3}$, XIA XUE $^{4}$ and YUN LUAN ${ }^{3}$ \\ ${ }^{1}$ Laboratory of Clinical Molecular Biology, ${ }^{2}$ Department of Pediatrics, ${ }^{3}$ Central Research Laboratory and \\ ${ }^{4}$ Department of Pharmacy, The Second Hospital of Shandong University, Jinan, Shandong 250033, P.R. China
}

Received May 23, 2017; Accepted February 28, 2018

DOI: $10.3892 /$ ijo.2018.4303

\begin{abstract}
The aim of the present study was to evaluate the effects of programmed cell death 4 (PDCD4) on cell proliferation and apoptosis, and to elucidate the potential role of the Jun N-terminal kinase (JNK)/c-Jun pathway in human bladder cancer $(\mathrm{BCa})$ cells. Mixed BCa cells were transfected with plasmids containing PDCD4 (PDCD4-pcDNA3). The sensitivity to cisplatin was analyzed using cell viability, invasion/migration, apoptosis, flow cytometry, wound healing and Transwell assays at different transfection times. Furthermore, epithelialto-mesenchymal transition (EMT) markers were detected by immunofluorescence staining, and the protein expression of c-Jun, and phosphorylated Jun N-terminal kinase (p-JNK) and c-Jun (p-c-Jun, Ser-73) were also tested using western blotting. It was observed that $\mathrm{BCa}$ cell proliferation and invasion and tumor growth were significantly inhibited, whereas apoptosis was enhanced in PDCD4-transfected cells treated with cisplatin compared with controls. Moreover, the western blotting and immunofluorescence results demonstrated that PDCD4 upregulated the expression of epithelial cell markers, but downregulated the expression of mesenchymal cell markers. Furthermore, overexpression of PDCD4 reduced the protein levels of p-JNK and p-c-Jun. Taken together, the findings of the present study indicate that PDCD4 enhances the sensitivity of BCa cells to cisplatin, partially via regulation of the JNK/c-Jun pathway, and reverses EMT. In conclusion, the results of the present study suggested that PDCD4, a nuclear/cytoplasmic shuttling protein with multiple functions, plays an important role in the development and progression of human $\mathrm{BCa}$.
\end{abstract}

\section{Introduction}

Bladder cancer $(\mathrm{BCa})$ is one of the most prevalent urinary tract malignancies worldwide $(1,2)$. Effective diagnostic and

Correspondence to: Dr Yun Luan, Central Research Laboratory, The Second Hospital of Shandong University, 247 Beiyuan Dajie, Jinan, Shandong 250033, P.R. China

E-mail: y_luan@aliyun.com

Key words: programmed cell death 4, bladder cancer, apoptosis, Jun N-terminal kinase/c-Jun, epithelial-to-mesenchymal transition therapeutic methods are available for patients with superficial disease, and the majority of these patients respond well to treatment; however, this type of cancer frequently recurs. Invasive and metastatic BCa remains a lethal malignancy $(3,4)$. Therefore, novel treatment strategies based on new molecular networks are urgently needed to improve the poor prognosis of patients with BCa. Programmed cell death protein 4 (PDCD4), a tumor suppressor, localizes to the nucleus and is associated with tumor progression and prognosis in a number of human cancers $(5,6)$.

Overexpression of PDCD4 has been shown to inhibit cell proliferation, and downregulation of PDCD4 has been identified in several cancerous tissues compared with adjacent normal tissues. PDCD4 plays a major role in a number of biological processes that may lead to tumor development. A variety of apoptosis inducers upregulate the expression of PDCD4, thus affecting multiple signaling pathways (7-9). c-Jun N-terminal kinase $(\mathrm{JNK})$ is a member of the mitogen-activated protein kinase (MAPK) family, and its activation is a requirement for the development of various cancers $(10,11)$. More recently, the JNK signaling pathway was found to play an important role in the proliferation and apoptosis of human BCa cells (12-14). Previous studies (15-17) have demonstrated that PDCD4 gene knockdown may increase the phosphorylation of c-Jun; hence, the transformation-suppressor function of PDCD4 may be due to the inhibition of c-Jun activity. Overexpression of miR-21 significantly promotes cell migration and invasion by targeting PDCD4 and activating its downstream c-Jun N-terminal kinase signaling pathway. These data indicate that PDCD4-related signal transduction through the JNK pathway may be a novel therapeutic target. However, the number of studies on PDCD4 and JNK signaling in BCa is limited, and the specific mechanism of action requires further elucidation. The aim of the present study was to evaluate the effects of PDCD4 on cell proliferation and apoptosis, and determine whether the mechanism of tumor cell inhibition by PDCD4 partially involves activation of the JNK/c-Jun pathway.

\section{Materials and methods}

Cell transfection. In the present study, EJ cells were used, which have been found to be contaminated by T2 4 cells, with the resultant cell line being a mixed $\mathrm{BCa}$ type. A large 
number of studies still use these cells for BCa research, and the contamination does not affect the outcomes of the experiments $(18,19)$. The BCa cells were purchased from the Shanghai Cell Bank of Chinese Academy of Sciences (Shanghai, China), and were maintained in RPMI-1640 (HyClone; GE Healthcare Life Sciences, Logan, UT, USA) supplemented with $10 \%(\mathrm{v} / \mathrm{v})$ heat-inactivated fetal bovine serum (FBS; Gibco; Thermo Fisher Scientific Inc., Waltham, MA, USA) containing $100 \mu / \mathrm{ml}$ penicillin and $100 \mathrm{mg} / \mathrm{ml}$ streptomycin in a humidified atmosphere of $5 \% \mathrm{CO}_{2}$ at $37^{\circ} \mathrm{C}$. Cells were harvested following a brief incubation in $0.02 \%(w / v)$ EDTA in phosphate-buffered saline (PBS). The cells were transfected with plasmids (pDsRed2-N1 and pDsRed2-N1-PDCD4) and assigned to three groups for the experiments as follows: $\mathrm{BCa}$, empty vector (mock) and PDCD4 transfection groups.

PDCD4 expression detection. The expression of PDCD4 was analyzed by reverse transcription-quantitative polymerase chain reaction (RT-qPCR) analysis and western blotting. Briefly, at $48 \mathrm{~h}$ after transfection, total RNA was extracted from cells using the Qiagen RNeasy kit (Qiagen, Basel, Switzerland), and reverse-transcribed with random primers for complementary DNA (cDNA) synthesis using the Reverse Transcription System (Promega, Madison, WI, USA). Primers were designed and synthesied as previously reported (20) and $\beta$-actin was used as a positive control. Each experiment was performed at least three times.

Total protein extracts were harvested using protein extraction buffer. Protein concentrations were assessed using a bicinchoninic acid protein assay kit (Santa Cruz Biotechnology, Inc., Dallas, TX, USA). Total protein (10 $\mu \mathrm{g})$ was separated by electrophoresis on 4-20\% SDS-PAGE gels and transferred to nitrocellulose membranes; the membranes were blocked with 5\% skimmed milk-Tris-buffered saline plus Tween-20 solution for $1 \mathrm{~h}$, followed by incubation at $4^{\circ} \mathrm{C}$ overnight with specific primary antibodies against PDCD4 [1:1,000, (D29C6) XP rabbit mAb, cat. no. 9535P] or human $\beta$-actin antibody [1:1,000, (D6A8) rabbit mAb, cat. no. 8457s] (both from Cell Signaling Technology, Inc., Danvers, MA, USA). Following incubation with peroxidase-conjugated AffiniPure goat anti-rabbit IgG (1:5,000; cat. no. ZB-2301; ZSGB-Bio Co., Ltd., Beijing, China), the bound antibodies were visualized using an enhanced chemiluminescence reagent (Millipore, Billerica, MA, USA) followed by Bio-Rad ImageLab ${ }^{\mathrm{TM}}$ (Bio-Rad Laboratories, Inc., Hercules, CA, USA). Data are expressed as the relative density of the protein normalized to $\beta$-actin. The percentages of the increase or decrease of protein were estimated by comparison to vehicle control (100\%).

Cell growth assay. Cells stably transfected with PDCD4 were plated in 48 -well plates at a density of $5 \times 10^{3}$ cells/well. After $6,12,24$ and $48 \mathrm{~h}$, the cells were collected, resuspended in PBS and treated with $2 \mu \mathrm{g} / \mathrm{ml}$ cisplatin for $24 \mathrm{~h}$. The cells were divided into the following five groups: $\mathrm{BCa}$ cells; empty vector (mock); mock + cisplatin; PDCD4; and PDCD4 + cisplatin. Cell growth and viability were evaluated by the 3-(4,5-dimethylthiazol-2-yl)-2,5-diphenyltetrazolium bromide (MTT) assay. The controls were treated with an equal volume of the drug vehicle dimethyl sulfoxide, but the applied concentration did not affect cell growth. The optical density of each culture was read by a Universal Microplate Reader at a wavelength of $570 \mathrm{~nm}$. The absorbance of the cells and growth inhibition ratio were calculated.

Wound healing assay. The cells were plated onto 24-well plates at a density of $5 \times 10^{5} /$ per well, and were grown for $48 \mathrm{~h}$ to a confluence of $>90 \%$. BCa cells stably transfected with PDCD4 at 0,12 and $24 \mathrm{~h}$ were treated with or without $2 \mu \mathrm{g} / \mathrm{ml}$ cisplatin and incubated for $24 \mathrm{~h}$ at $37^{\circ} \mathrm{C}$ under $5 \% \mathrm{CO}_{2}$. A wound (cell-free area) was created by manually scraping the cell monolayer with a $10-\mu 1$ plastic pipette tip. Cell debris was removed and the cells were then cultured in RPMI-1640 containing 1\% FBS. Images (magnification, $\mathrm{x} 40$ ) were captured using a Nikon Eclipse 90i microscope (Nikon Corporation, Tokyo, Japan). The experiments were repeated three times.

Cell migration assay. The migratory function of mixed BCa cells was evaluated using a modified Boyden chamber (Transwell; Corning Life Sciences, Inc., Tewksbury, MA, USA) assay with a polycarbonate filter with $8-\mu \mathrm{m}$ pores placed between the upper and lower chambers. In brief, at 0 and $24 \mathrm{~h}$ following transfection, cells were treated with or without $2 \mu \mathrm{g} / \mathrm{ml}$ cisplatin containing 1\% FBS and added $\left(1 \times 10^{6}\right.$ cells/100 $\left.\mu \mathrm{l}\right)$ to the upper chamber. The lower chamber was filled with complete medium in the presence of $10 \%$ FBS. After a 48 -h incubation at $37^{\circ} \mathrm{C}$ under $5 \% \mathrm{CO}_{2}$, cells that had not migrated were removed, whereas migrated cells were fixed in $4 \%$ paraformaldehyde for $10 \mathrm{~min}$ at room temperature and stained with the Crystal Violet Staining Solution kit (Solarbio, Beijing Solarbio Science \& Technology Co., Ltd., Beijing, China). The number of migrated cells was counted using a Nikon Eclipse 90i microscope.

Flow cytometry and apoptosis assay. The Annexin V-FITC/PI apoptosis detection kit was used according to the manufacturer's instructions, as previously reported (21). Briefly, cells were transfected at 12 and $24 \mathrm{~h}$, then treated with or without $2 \mu \mathrm{g} / \mathrm{ml}$ cisplatin and incubated for a further $24 \mathrm{~h}$ at $37^{\circ} \mathrm{C}$ under $5 \% \mathrm{CO}_{2}$ in 6-well plates. The cells $\left(1 \times 10^{6}\right)$ were collected and suspended in $500 \mu \mathrm{l}$ binding buffer, and $5 \mu \mathrm{l}$ Annexin V-FITC and $5 \mu \mathrm{l}$ PI were added to each sample and incubated for $15 \mathrm{~min}$ in the dark. The cell surface phosphatidylserine was quantitatively estimated in apoptotic cells by using the Annexin V/FITC apoptosis detection kit according to the manufacturer's instructions (Roche Diagnostics, Indianapolis, IN, USA). Data were detected using FACScan flow cytometry (FACS LSRFortessa; BD Biosciences, Franklin Lakes, NJ, USA). Triplicate experiments with triplicate samples were performed.

Epithelial-to-mesenchymal transition (EMT) markers and immunofluorescence staining analysis. E-cadherin, vimentin and $\mathrm{N}$-cadherin were detected by cell immunofluorescence techniques to investigate the EMT signaling pathway-related markers. Briefly, cells in each group under different conditions were seeded on coverslips in 6-well plates ( $1 \times 10^{5} /$ well) for $24 \mathrm{~h}$, fixed in $4 \%$ paraformaldehyde for $30 \mathrm{~min}$ and washed three times with PBS. The slips were permeabilized for $10 \mathrm{~min}$ with $0.1 \%$ Triton X-100 and washed three times with PBS, and the cells were then blocked with $10 \%$ normal goat serum for $30 \mathrm{~min}$. 
A
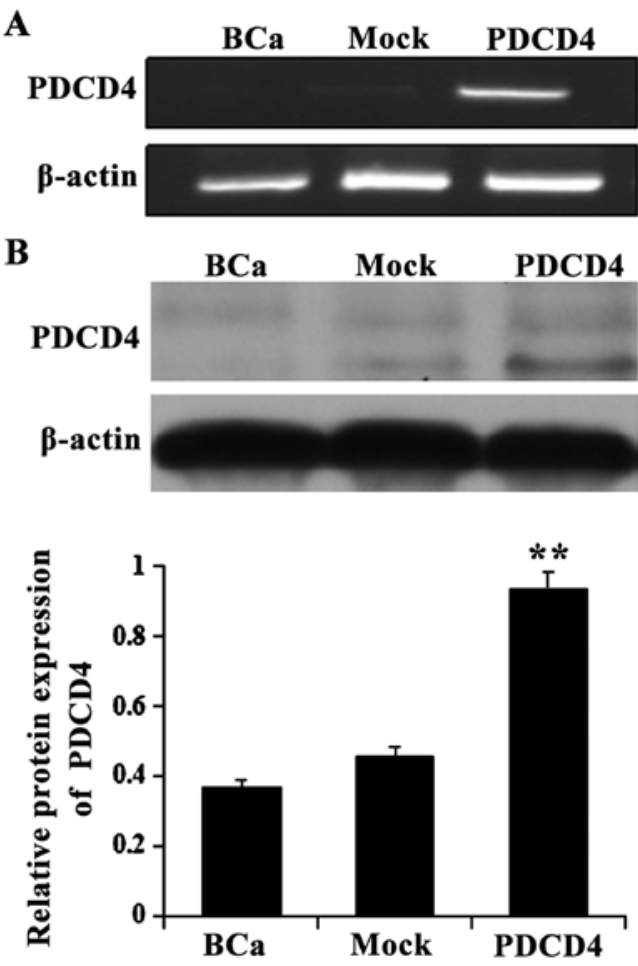

Figure 1. Overexpression of programmed cell death 4 (PDCD4) in bladder cancer $(\mathrm{BCa})$ cells were examined by reverse transcription-polymerase chain reaction (RT-PCR) and western blotting. (A) RT-PCR; (B) Western blotting. PDCD4 mRNA and protein expression were significantly higher in PDCD4-transfected cells compared with empty vector (mock) group. The data are present as mean \pm standard deviation. ${ }^{* *} \mathrm{P}<0.01$ compared with the BCa group.

The cells were incubated overnight at $4^{\circ} \mathrm{C}$ with primary antibodies against E-cadherin (1:50 dilution; sc-7870), vimentin (1:200, ab92547; Abcam) and N-cadherin (1:50, sc-7939), followed by incubation for $1 \mathrm{~h}$ in the dark with fluorescein isothiocyanate-conjugated and tetraethyl rhodamine isothiocyanate goat anti-rabbit secondary antibody (ZSGB-Bio Co., Beijing, China). Fluorescent images were captured with a Nikon Eclipse 90i microscope. The staining results were analyzed with the Image-Pro Plus 6 image-analyzing system (Media Cybernetics, Inc., Rockville, MD, USA).

Western blotting. To further investigate the potential role of PDCD4 in BCa cells and the possible underlying mechanism, western blotting was performed to analyze the protein expression of JNK signaling pathway and EMT markers. Blots were probed with specific primary antibodies: c-Jun (1:1,000, no. 9165), p-JNK (1:1,000, no. 4668) and p(Ser-73)-c-Jun (1:1,000, no. 9261/no. 3270) (Cell Signaling Technology, Beverly, MA, USA), E-cadherin, vimentin, $\mathrm{N}$-cadherin and matrix metalloproteinase-9 (MMP-9). The peroxidase-conjugated AffiniPure goat anti-rabbit IgG secondary antibody was added, followed by incubation at $37^{\circ} \mathrm{C}$ for $1 \mathrm{~h}$. The bound antibodies were visualized using an enhanced chemiluminescence reagent (Millipore) followed by analysis with Bio-Rad Image $\mathrm{Lab}^{\mathrm{TM}}$. Data are expressed as the relative density of the protein normalized to $\beta$-actin. The percentages of increase or decrease of the protein level were estimated by comparison to vehicle control (100\%).

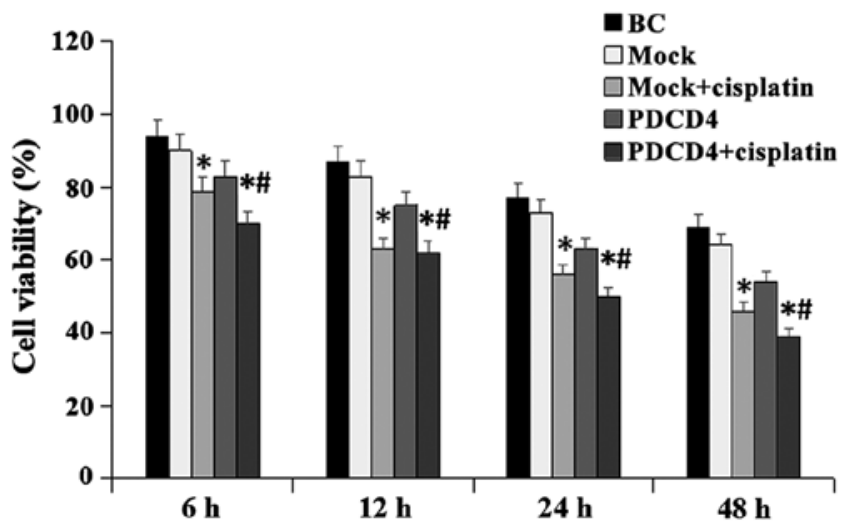

Figure 2. Effect of programmed cell death 4 (PDCD4) overexpression and cisplatin sensitivity analysis. Overexpression of PDCD4 significantly suppressed the growth of bladder cancer $(\mathrm{BCa})$ cells compared with mock cells. When the cells were treated with $2 \mu \mathrm{g} / \mathrm{ml}$ cisplatin, the growth inhibition ratio was obviously lower in the PDCD4 group compared with that in the group without treatment. The data are presented as mean \pm standard deviation. ${ }^{*} \mathrm{P}<0.05$ compared with the $\mathrm{BCa}$ group; ${ }^{\#} \mathrm{P}<0.05$ compared with the mock + cisplatin group.

Statistical analysis. Statistical analyses were performed with one-way analysis of variance followed by the Bonferroni test or t-test when appropriate, using the SPSS statistical software, version 10.0 (SPSS, Inc., Chicago, IL, USA). P $<0.05$ was considered to indicate statistically significant differences. Data of continuous variables are presented as the mean \pm standard deviation.

\section{Results}

Overexpression of PDCD4 in $\mathrm{BCa}$ cells. To provide direct evidence that PDCD4 inhibits the proliferation of BCa cells, we introduced recombinant $\mathrm{pDsRed2-N1}$ plasmids that carry the full-length PDCD4 cDNA, as well as parental vector controls into the cells, which express only low levels of endogenous PDCD4. RT-PCR and western blot analysis revealed that cells transfected with the PDCD4 expression plasmid exhibited stronger PDCD4 expression compared with the control cells $(\mathrm{P}<0.05$; Fig. 1). These results indicate that the recombinant pDsRed2-N1-PDCD4 plasmid promoted PDCD4 expression in $\mathrm{BCa}$ cells.

PDCD4 overexpression inhibits cell viability and improves sensitivity to cisplatin. Following transfection, the effect of PDCD4 on cell growth was further investigated. The results revealed that, when the cells were treated with $2 \mu \mathrm{g} / \mathrm{ml}$ cisplatin for $24 \mathrm{~h}$, overexpression of PDCD4 significantly inhibited the viability of $\mathrm{BCa}$ cells compared with cells without treatment $(\mathrm{P}<0.05 ;$ Fig. 2). Our results indicated that enforced expression of PDCD4 was associated with cisplatin sensitivity in $\mathrm{BCa}$ cells.

PDCD4 overexpression inhibits cell migration and invasion. The migration and invasion properties of cells in each group under different conditions were evaluated. As demonstrated in Fig. 3, the migration of cells was significantly inhibited in the PDCD4 group compared with the mock group at 12 and $24 \mathrm{~h}$, as measured by the wound healing assay. Similarly, 

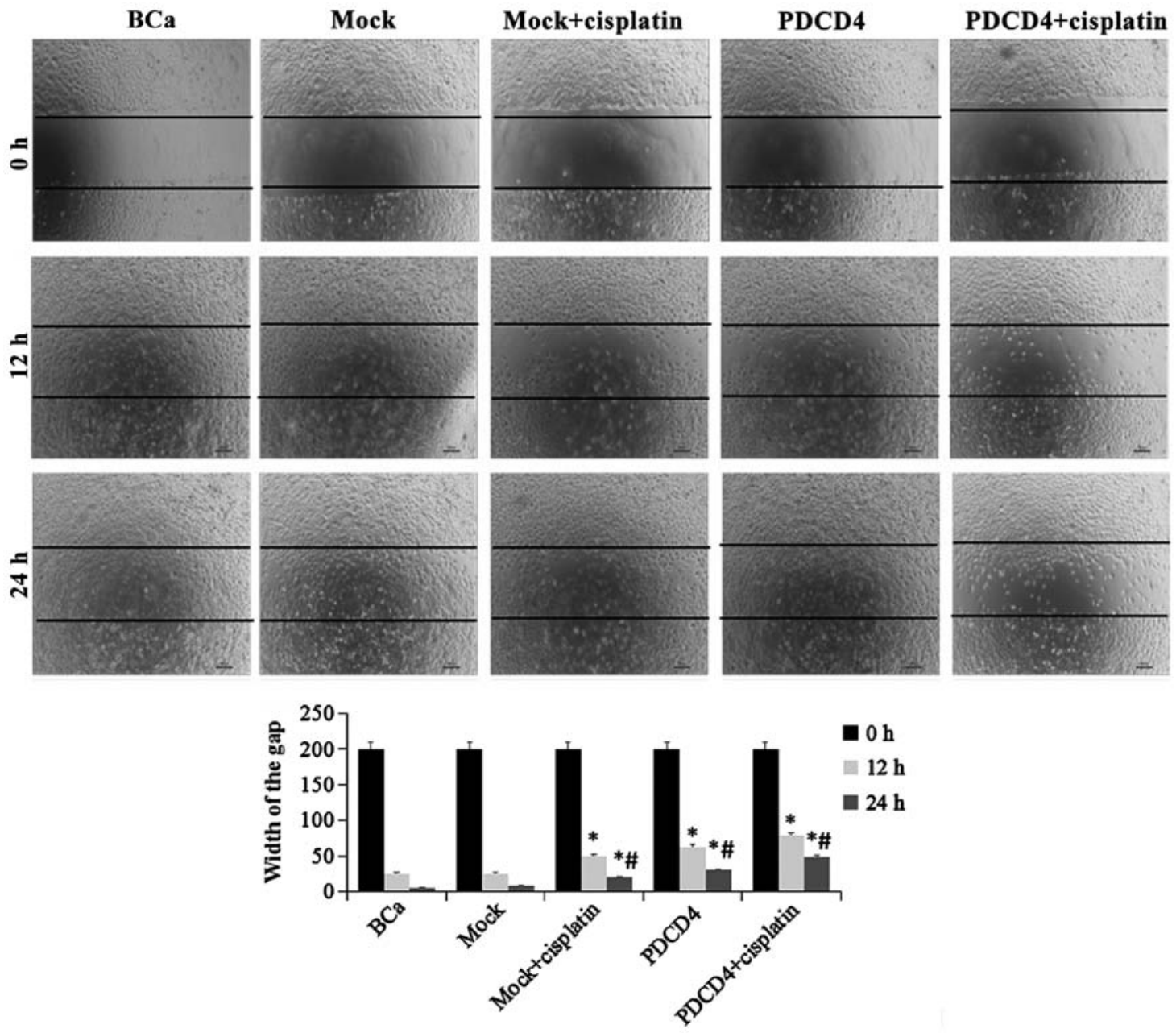

Figure 3. Cell migration detected by wound healing assay. Overexpression of programmed cell death 4 (PDCD4) significantly inhibited the migration of bladder cancer (BCa) cells at 12 and $24 \mathrm{~h}$ (magnification, $\mathrm{x} 40$ ). The data are presented as mean \pm standard deviation. " $\mathrm{P}<0.05$ compared with the BCa group; ${ }^{\text {"}} \mathrm{P}<0.05$ compared with the mock + cisplatin group.

invasion, as assessed by the Transwell assay, was also markedly suppressed in the PDCD4 group compared with the mock group at $24 \mathrm{~h}(\mathrm{P}<0.05$; Fig. 4). Furthermore, after PDCD4transfected cells were treated with cisplatin, their migration and invasion ability were clearly lower compared with those in the mock + cisplatin and PDCD4 groups. These results indicated that, in addition to its cytotoxic effect, PDCD4 overexpression increased the sensitivity to cisplatin in $\mathrm{BCa}$ cells.

PDCD4 overexpression induces BCa cell apoptosis. To evaluate the effect of PDCD4 overexpression on BCa cell apoptosis, the cells in each group under different conditions were stained with Annexin V/FITC and analyzed by flow cytometry. As shown in Fig. 5, the percentage of apoptotic cells gradually increased after 12 and $24 \mathrm{~h}$ of treatment with cisplatin $(\mathrm{P}<0.05)$. Of note, there was a more prominent elevation of the positive ratio in PDCD4 cells compared with mock cells when they were treated with cisplatin $(\mathrm{P}<0.05)$.

PDCD4 overexpression inhibits the expression of EMT markers. In order to investigate the mechanism underlying the inhibitory effect of PDCD4 on BCa cells, the EMT transition signal pathway-related markers were detected by cell immunofluorescence techniques and western blotting.
As shown in Fig. 6, the immunofluorescence techniques revealed that the expression of E-cadherin was significantly decreased, whereas that of vimentin and $\mathrm{N}$-cadherin was significantly increased when the cells were treated with cisplatin for $24 \mathrm{~h}$ in the PDCD4 + cisplatin group compared with the mock + cisplatin group.

The western blotting results also demonstrated that the protein expression of E-cadherin and the EMT-associated protein MMP-9 was upregulated, but vimentin and N-cadherin were downregulated when the cells were treated with cisplatin for $24 \mathrm{~h}$ in the PDCD4 + cisplatin group compared with the mock + cisplatin group $(\mathrm{P}<0.05$; Fig. 7$)$.

These results revealed that overexpression of PDCD4 enhances the efficiency of EMT inhibition when the cells are treated with cisplatin.

Effect of PDCD4 overexpression on protein levels of the JNK signaling pathway. We analyzed the protein expression levels of JNK, c-Jun, p-JNK and p-c-Jun Ser73 by western blotting. As demonstrated in Fig. 8, the protein levels of JNK and c-Jun were increased in the mock and PDCD4 groups compared with the $\mathrm{BCa}$ group $(\mathrm{P}<0.05)$, with no significant difference $(\mathrm{P}>0.05)$ between the mock and PDCD4 groups. The expression of p-JNK and p-c-Jun Ser73 was obviously increased in 

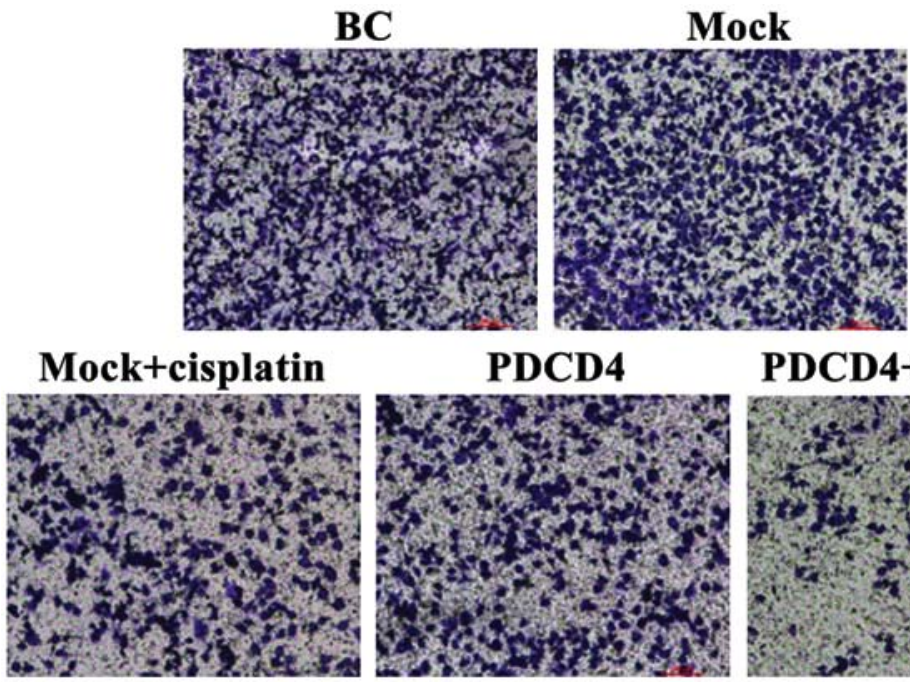

PDCD4+cisplatin

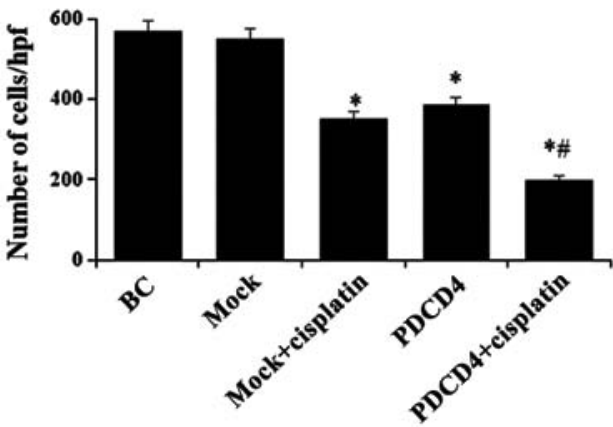

Figure 4. Cell invasion detected by Transwell analysis. Overexpression of programmed cell death 4 (PDCD4) significantly inhibited the invasion of bladder cancer (BCa) cells at $24 \mathrm{~h}$ (magnification, $\mathrm{x} 100$ ). The number of cells was expressed per high-power field $\left(\mathrm{hpf}, 0.2 \mathrm{~mm}^{2}\right)$.The data are presented as mean \pm standard deviation. ${ }^{*} \mathrm{P}<0.05$ compared with the $\mathrm{BCa}$ group; ${ }^{*} \mathrm{P}<0.05$ compared with the mock + cisplatin group.
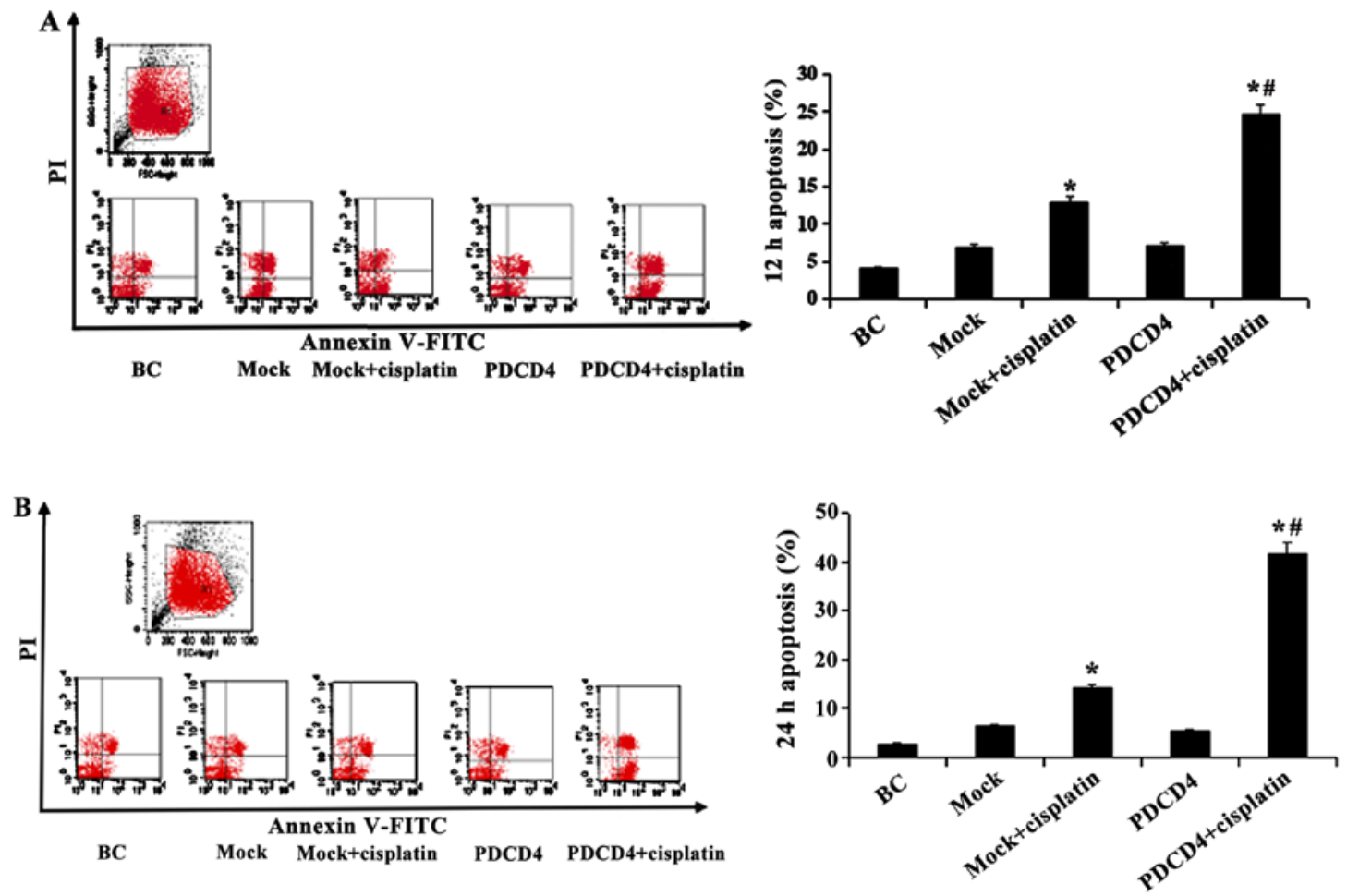

Figure 5. Cell apoptosis by flow cytometry. Cells were stained with Annexin V/FITC and then analyzed by flow cytometry. The percentage of apoptotic cells gradually increased following treatment for 12 and $24 \mathrm{~h}$ in the cisplatin group. This increase of the positive ratio was more prominent in programmed cell death 4 (PDCD4) + cisplatin group cells compared with empty vector (mock) cells. (A) $12 \mathrm{~h}$, (B) $24 \mathrm{~h}$. The data are presented as mean \pm standard deviation. ${ }^{*} \mathrm{P}<0.05$ compared with the bladder cancer $(\mathrm{BCa})$ group; ${ }^{*} \mathrm{P}<0.05$ compared with the mock + cisplatin group. 

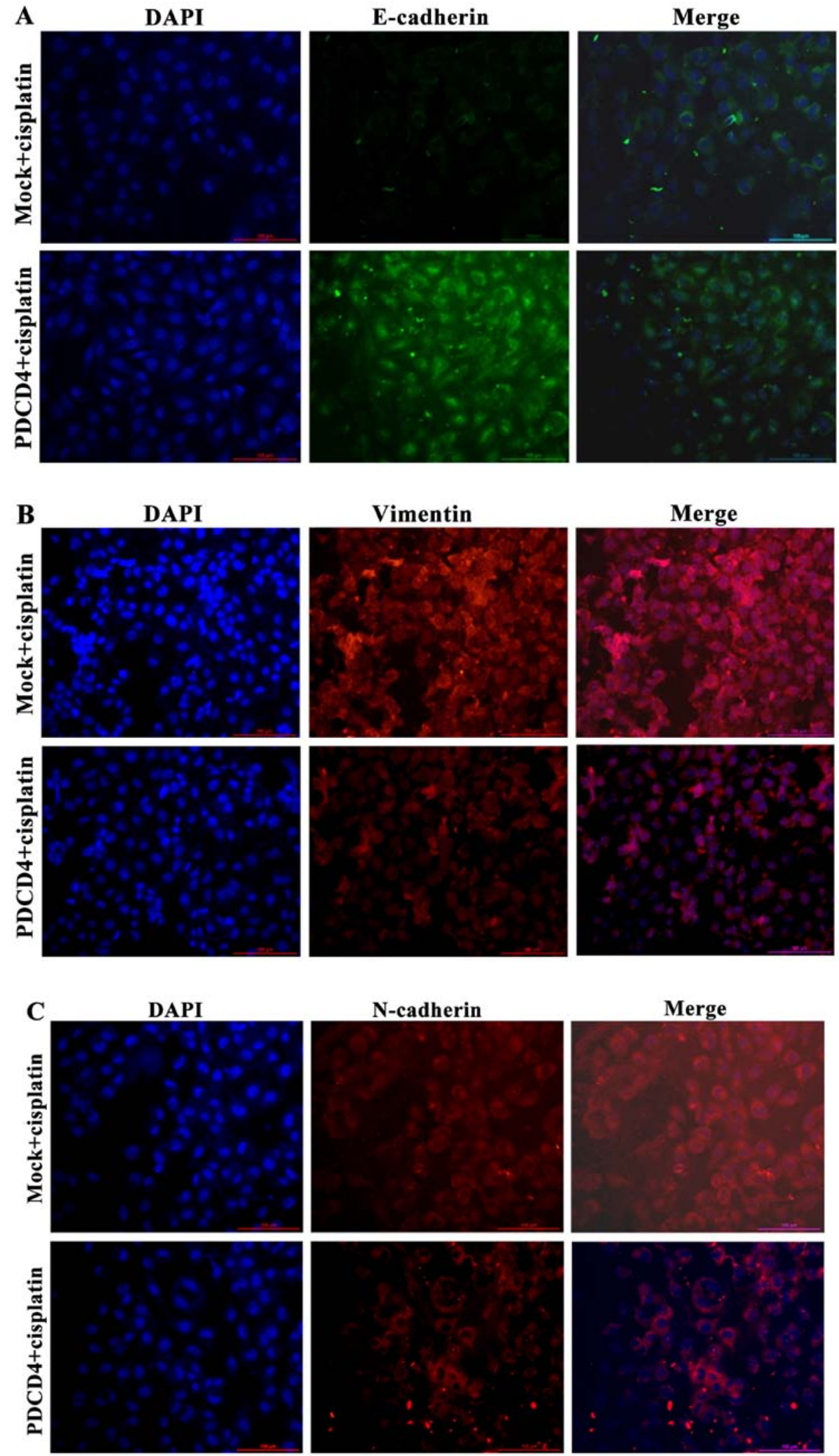

Figure 6. Epithelial-to-mesenchymal transition-related markers detected by immunofluorescence analysis. The expression level of E-cadherin was significantly upregulated, but vimentin and $\mathrm{N}$-cadherin were significantly downregulated when the cells were treated with cisplatin for $24 \mathrm{~h}$ in the programmed cell death 4 (PDCD4) + cisplatin group compared with the mock + cisplatin group. (A) E-cadherin. (B) Vimentin. (C) N-cadherin (magnification, x200). DAPI, 4',6-diamidino-2-phenylindole.

the mock and PDCD4 groups compared with the BCa group $(\mathrm{P}<0.05)$; moreover, the expression of $\mathrm{p}-\mathrm{JNK}$ and $\mathrm{p}-\mathrm{c}-\mathrm{Jun}$
Ser73 was significantly decreased in the PDCD4 group compared with the mock group $(\mathrm{P}<0.05)$. Taken together, these 

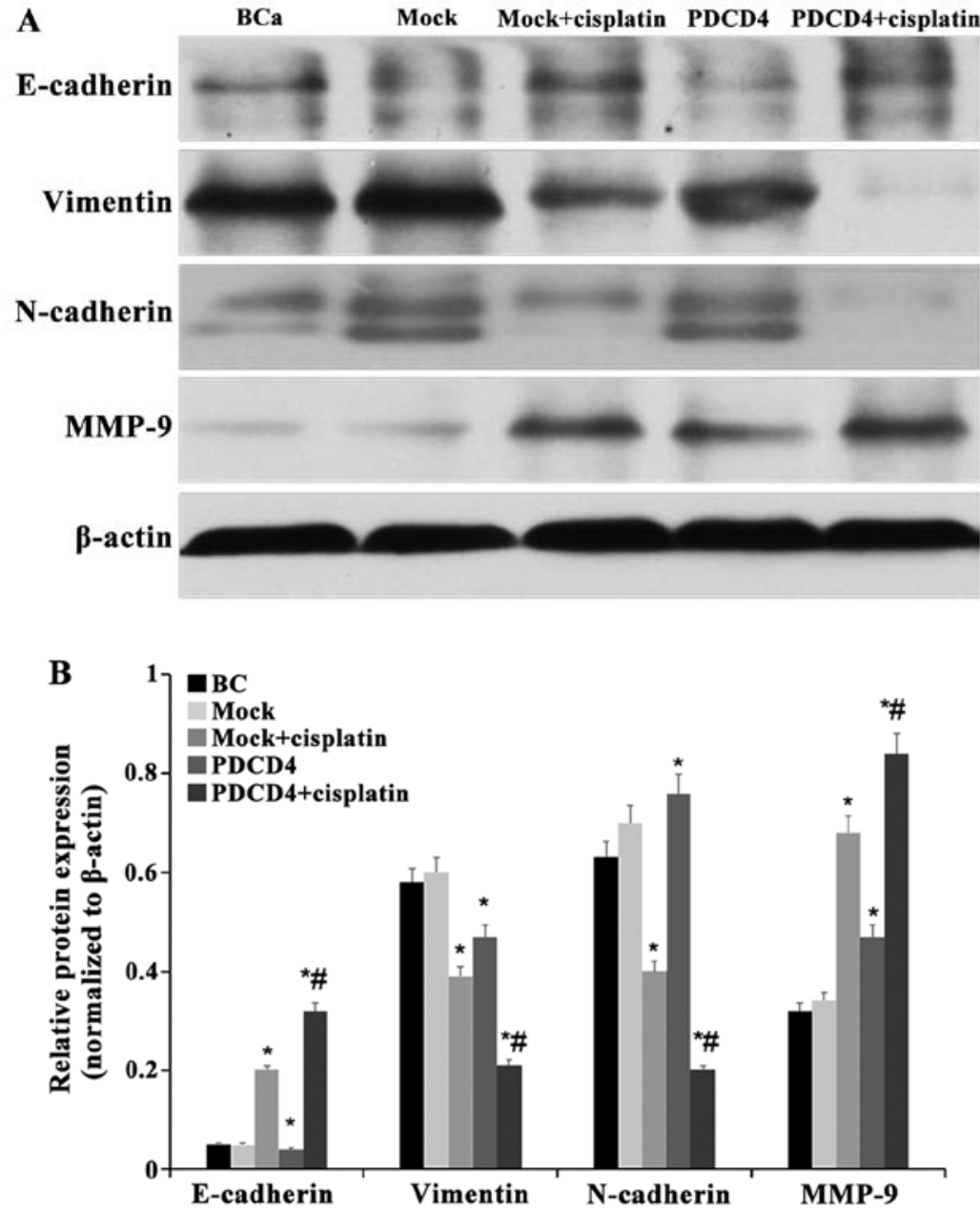

Figure 7. Protein expression of epithelial-to-mesenchymal transition-related markers detected by (A) western blotting. Programmed cell death 4 (PDCD4) overexpression inhibited the protein expression of epithelial-to-mesenchymal transition-related markers in bladder cancer (BCa) cells. (B) A comparison of the protein levels of the epithelial-to-mesenchymal transition-related markers. The data are presented as mean \pm standard deviation. ${ }^{*} \mathrm{P}<0.05$ compared with the $\mathrm{BCa}$ group; ${ }^{\#} \mathrm{P}<0.05$ compared with the mock group. MMP, matrix metelloproteinase.
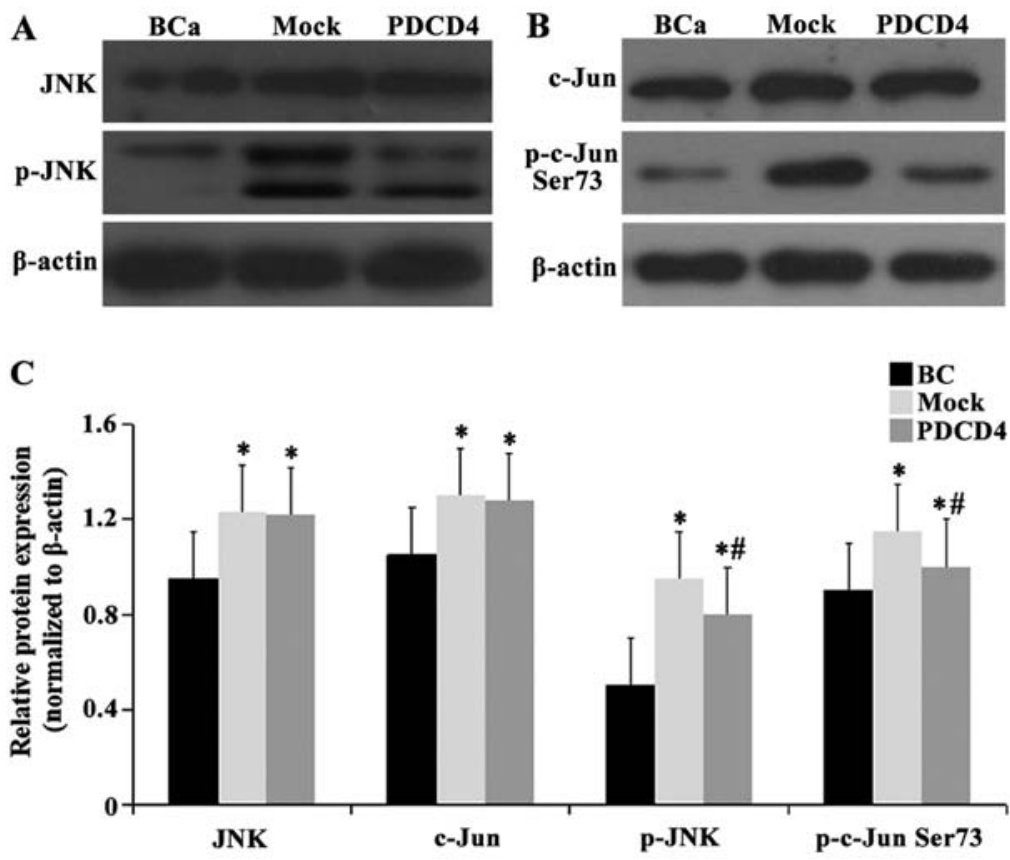

Figure 8. Effect of programmed cell death 4 (PDCD4) overexpression on the protein levels of the Jun N-terminal kinase (JNK)/c-Jun signaling pathway. (A) The protein levels of JNK and p-JNK, (B) protein levels of c-Jun, and p-c-Jun (Ser73). (C) A comparison of the protein levels of the JNK/c-Jun signaling pathway. The data are presented as mean \pm standard deviation. ${ }^{*} \mathrm{P}<0.05$ compared with the bladder cancer $(\mathrm{BCa})$ group; ${ }^{*} \mathrm{P}<0.05$ compared with the mock group. 
findings demonstrated that the enhancement in the sensitivity of cells to cisplatin is partially mediated via regulation of the JNK/c-Jun pathway.

\section{Discussion}

To the best of our knowledge, the present study is the first to demonstrate that PDCD4 overexpression in $\mathrm{BCa}$ can inhibit cancer cell proliferation and invasion and tumor growth, and enhance sensitivity to cisplatin, possibly through activation of the JNK/c-Jun signaling pathway, further suppressing the EMT process.

PDCD4 is a tumor suppressor gene that is involved in cell apoptosis, transformation and invasion, as well as tumor progression (22). Targeted inhibition of PDCD4 significantly enhanced cancer cell migration and invasion in hepatocellular carcinoma (23). More recently, PDCD4 has been shown to suppress $\mathrm{BCa}$ progression, and increased PDCD4 expression efficiently sensitized muscle-invasive $\mathrm{BCa}$ cells to cisplatin chemotherapy and suppressed cell invasiveness (24). However, the mechanisms underlying PDCD4-induced apoptosis have yet to be fully elucidated. Modulation of the JNK1/2 signaling pathway by PDCD4, particularly c-Jun/AP-1-dependent transcription through the downstream MAP4K1/JNK/AP-1 signaling pathway, suggests that this is a novel upstream target of this signaling cascade (25). Increased c-Jun phosphorylation was positively correlated with clinical grade in BCa tissues, and deregulation of c-Jun has been reported in several different types of cancer, including its overexpression in BCa (26). Mitochondria-related apoptosis in human BCa cells is also associated with activation of the JNK signaling pathway (27). In the present study, we found that cell proliferation, invasion and tumor growth were significantly inhibited, whereas cell apoptosis was enhanced in the PDCD4 transfection group compared with the mock group in $\mathrm{BCa}$ cells when they were treated with cisplatin. More importantly, we found that PDCD4 overexpression reduced the protein levels of p-JNK and p-c-Jun. Collectively, the findings of our study suggest that PDCD4 potentiates the antitumor activity of cisplatin against human $\mathrm{BCa}$ cells by inhibiting cell proliferation and invasion and promoting apoptosis, partly via activation of the JNK/c-Jun pathway.

EMT is a complex and reversible process characterized by the loss of intercellular cohesion and epithelial makers. Recent studies reported that EMT promotes cell migration and invasion in multiple types of cancer, and it is crucial for the invasiveness and metastasis of $\mathrm{BCa}(17,28)$. EMT is characterized by the acquisition of a mesenchymal phenotype and loss of epithelial cell polarity, includes conversion of epithelial cells to a fibroblastoid phenotype, and involves downregulation of the epithelial-specific protein E-cadherin and upregulation of the mesenchymal-specific proteins $\mathrm{N}$-cadherin and vimentin, increasing migration through the extracellular matrix (29). This switch leads to loss of the affinity for neighboring epithelial cells and development of affinity for mesenchymal cells, resulting in increased migration and invasion (9). It has been demonstrated that the association between the MMP family and EMT plays an important role in different types of cancer, such as lung, ovarian, liver and breast cancer (30-33), and knockdown of
PDCD4 may lead to EMT, changes in adhesion, and promotion of migration and metastasis. These data indicated that both PDCD4 and EMT play important roles in the progression of cancer; however, the mechanisms underlying the interaction between PDCD4 and EMT signaling pathways has not been fully elucidated. Recent studies also demonstrated that the development and progression of $\mathrm{BCa}$ are associated with the involvement of both EMT and MMPs (34). MMP-2 and MMP-9 are involved in the metastatic spread of various tumors, including transitional cell carcinoma and $\mathrm{BCa}(35,36)$. We herein demonstrated that PDCD4 + cisplatin significantly downregulated the protein expression levels of epithelial marker E-cadherin and MMP-9, while upregulating the mesenchymal markers vimentin and $\mathrm{N}$-cadherin compared with the mock + cisplatin group. Based on these results, it was hypothesized that PDCD4 may enhance the sensitivity of $\mathrm{BCa}$ cells to cisplatin via inhibition of the MMP-related EMT process. Suppression of cell migration, invasion and adhesive ability caused by EMT may be mediated via inhibition of JNK-related pathways $(37,38)$. JNKs increase circulating tumor cell survival and tissue homing, promote cell attachment to the endothelium, stimulate EMT to facilitate tumor cell extravasation, and enhance the secretion of endothelial barrier disrupters (39). Reversing EMT to inhibit gastric cancer cell metastasis and suppressing the expression of MMP-9 and MMP-2 may be mediated via the JNK and extracellular-regulated kinase signaling pathways (40). Of note, the present study also demonstrated that PDCD4 overexpression markedly reduced the protein levels of p-JNK and p-c-Jun. Taken together, our data suggest that PDCD4 increases the antitumor activity of cisplatin against human $\mathrm{BCa}$ cells through activation of the JNK/c-Jun pathway and further suppression of the EMT process.

Modulating immune inhibitory pathways has been a major recent breakthrough in cancer treatment. Checkpoint blockade antibodies targeting cytotoxic T-lymphocyte antigen 4 and programed cell-death protein 1 (PD-1) have demonstrated acceptable toxicity (41). The discovery of PD-1 and its ligand 1 (PD-L1) has introduced a modern era of cancer immunotherapy. Blocking the PD-1 pathway using monoclonal antibodies against PD-1 or PD-L1 may therefore revamp the immune response against tumor cells (42). Several anti-PD agents have been approved for BCa therapy. Our current data may be able to be incorporated and used together with these novel agents, and the results of the present study may help design new checkpoint blockade therapies targeted at PDCD4 in the future.

In summary, our results suggest that PDCD4, a nuclear/cytoplasmic shuttling protein with multiple functions, plays an important role in the development and progression of human $\mathrm{BCa}$. The mechanism underlying the increased sensitivity of BCa cells to cisplatin may be mediated via the JNK/c-Jun signaling pathway, further reversing the MMP-related EMT process.

\section{Acknowledgements}

The authors are grateful to Central Research Laboratory of the Second Hospital of Shandong University for the technical assistance and generous support. 


\section{Funding}

The present study was supported by the National Natural Science Foundation of China (grant no. 81500042), the Natural Science Foundation of Shandong Province (grant no. ZR2016HM67), the Science and Technology Development Project of Shandong Province (grant nos. 2016GSF201044 and 2016GSF201203), and the Medical and Health Science Technology Development Plan Project of Shandong Province (grant no. 2015WS0307).

\section{Availability of data and materials}

All data generated or analyzed during this study are included in this published article.

\section{Authors' contributions}

YL designed the research and oversaw the writing of the manuscript; JL, RZ, JW, QX and XX performed the experiments and wrote the manuscript, and FK, JZ analyzed the data. All authors have read and approved the manuscript.

\section{Ethics approval and consent to participate}

Not applicable.

\section{Consent for publication}

Not applicable.

\section{Competing interests}

The authors declare that they have no competing interests.

\section{References}

1. Wu CL, Ho JY, Chou SC and Yu DS: miR-429 reverses epithelialmesenchymal transition by restoring E-cadherin expression in bladder cancer. Oncotarget 7: 26593-26603, 2016.

2. Rao Q, Chen Y, Yeh CR, Ding J, Li L, Chang C and Yeh S: Recruited mast cells in the tumor microenvironment enhance bladder cancer metastasis via modulation of ER $\beta / C C L 2 / C C R 2$ EMT/MMP9 signals. Oncotarget 7: 7842-7855, 2016.

3. Wu CT, Chang YH, Lin P, Chen WC and Chen MF: Thrombomodulin expression regulates tumorigenesis in bladder cancer. BMC Cancer 14: 375, 2014.

4. Shirodkar SP and Lokeshwar VB: Potential new urinary markers in the early detection of bladder cancer. Curr Opin Urol 19 488-493, 2009.

5. Asangani IA, Rasheed SA, Nikolova DA, Leupold JH, Colburn NH, Post S and Allgayer H: MicroRNA-21 (miR-21) post-transcriptionally downregulates tumor suppressor Pdcd4 and stimulates invasion, intravasation and metastasis in colorectal cancer. Oncogene 27: 2128-2136, 2008

6. Yu H,Zeng J,Liang X, Wang W,Zhou Y, Sun Y,Liu S, Li W, Chen C and Jia J: Helicobacter pylori promotes epithelial-mesenchymal transition in gastric cancer by downregulating programmed cell death protein 4 (PDCD4). PLoS One 9: e105306, 2014.

7. Ferraro A, Kontos CK, Boni T, Bantounas I, Siakouli D, Kosmidou V, Vlassi M, Spyridakis Y, Tsipras I, Zografos G, et al: Epigenetic regulation of miR-21 in colorectal cancer: ITGB4 as a novel miR-21 target and a three-gene network (miR-21-ITGß4-PDCD4) as predictor of metastatic tumor potential. Epigenetics 9: 129-141, 2014

8. Brønnum H, Andersen DC, Schneider M, Sandberg MB, Eskildsen T, Nielsen SB, Kalluri R and Sheikh SP: miR-21 promotes fibrogenic epithelial-to-mesenchymal transition of epicardial mesothelial cells involving Programmed Cell Death 4 and Sprouty-1. PLoS One 8: e56280, 2013.
9. Wang Q, Zhu J, Zhang Y, Sun Z, Guo X, Wang X, Lee E, Bakthavatchalu V, Yang Q and Yang HS: Down-regulation of programmed cell death 4 leads to epithelial to mesenchymal transition and promotes metastasis in mice. Eur J Cancer 49: 1761-1770, 2013.

10. Wang X, Wu H, Lakdawala VS, Hu F, Hanson ND and Miller AH: Inhibition of Jun N-terminal kinase (JNK) enhances glucocorticoid receptor-mediated function in mouse hippocampal HT22 cells. Neuropsychopharmacology 30: 242-249, 2005.

11. Wagner EF and Nebreda AR: Signal integration by JNK and p38 MAPK pathways in cancer development. Nat Rev Cancer 9: 537-549, 2009.

12. Fang Y, Wang Y, Wang Y, Meng Y, Zhu J, Jin H, Li J, Zhang D, $\mathrm{Yu} \mathrm{Y}, \mathrm{Wu} \mathrm{XR}$, et al: A new tumour suppression mechanism by p27Kip1: EGFR down-regulation mediated by JNK/c-Jun pathway inhibition. Biochem J 463: 383-392, 2014.

13. Gong Y, Qiu W, Ning X, Yang X, Liu L, Wang Z, Lin J, Li X and Guo Y: CCDC34 is up-regulated in bladder cancer and regulates bladder cancer cell proliferation, apoptosis and migration. Oncotarget 6: 25856-25867, 2015.

14. Shen KH, Li CF, Chien LH, Huang CH, Su CC, Liao AC and Wu TF: Role of galectin-1 in urinary bladder urothelial carcinoma cell invasion through the JNK pathway. Cancer Sci 107: 1390-1398, 2016.

15. Subedi A, Kim MJ, Nepal S, Lee ES, Kim JA, Sohn DH, Song K, Lee SH, Park WS, Jeong BS, et al: Globular adiponectin modulates expression of programmed cell death 4 and miR-21 in RAW 264.7 macrophages through the MAPK/NF- $\kappa \mathrm{B}$ pathway. FEBS Lett 587: 1556-1561, 2013.

16. Wang Q, Zhang Y and Yang HS: Pdcd4 knockdown up-regulates MAP4K1 expression and activation of AP-1 dependent transcription through c-Myc. Biochim Biophys Acta 1823: 1807-1814, 2012.

17. Echevarría-Vargas IM, Valiyeva $F$ and Vivas-Mejía PE: Upregulation of miR-21 in cisplatin resistant ovarian cancer via JNK-1/c-Jun pathway. PLoS One 9: e97094, 2014.

18. Song Y, Zhang P, Sun Y, Li X, Chen L, Xiao Y and Xing Y: AMPK activation-dependent autophagy compromises oleanolic acid-induced cytotoxicity in human bladder cancer cells. Oncotarget 8: 67942-67954, 2017.

19. Huang B, Zhang J, Zhang X, Huang C, Hu G, Li S, Xie T, Liu M and Xu Y: Suppression of LETM1 by siRNA inhibits cell proliferation and invasion of bladder cancer cells. Oncol Rep 38: 2935-2940, 2017

20. Wei ZT, Zhang X, Wang XY, Gao F, Zhou CJ, Zhu FL, Wang Q, Gao Q, Ma CH, Sun WS, et al: PDCD4 inhibits the malignant phenotype of ovarian cancer cells. Cancer Sci 100: 1408-1413, 2009.

21. Luan Y, Liu J, Liu X, Xue X, Kong F, Sun C, Wang J, Liu L and Jia H: Tetramethypyrazine inhibits renal cell carcinoma cells through inhibition of NKG2D signaling pathways. Int J Oncol 49: 1704-1712, 2016

22. Wei X, Wang W, Wang L, Zhang Y, Zhang X, Chen M, Wang F, Yu J, Ma Y and Sun G: MicroRNA-21 induces 5-fluorouracil resistance in human pancreatic cancer cells by regulating PTEN and PDCD4. Cancer Med 5: 693-702, 2016.

23. Selaru FM, Olaru AV, Kan T, David S, Cheng Y, Mori Y, Yang J, Paun B, Jin Z, Agarwal R, et al: MicroRNA-21 is overexpressed in human cholangiocarcinoma and regulates programmed cell death 4 and tissue inhibitor of metalloproteinase 3. Hepatology 49: $1595-1601,2009$

24. Lei Y, Hu X, Li B, Peng M, Tong S, Zu X, Wang Z, Qi L and Chen M: miR-150 modulates cisplatin chemosensitivity and invasiveness of muscle-invasive bladder cancer cells via targeting PDCD4 in vitro. Med Sci Monit 20: 1850-1857, 2014.

25. Ferreira DM, A fonso MB, Rodrigues PM, Simão AL, Pereira DM, Borralho PM, Rodrigues CM and Castro RE: c-Jun N-terminal kinase $1 / \mathrm{c}-J$ un activation of the p53/microRNA 34a/sirtuin 1 pathway contributes to apoptosis induced by deoxycholic acid in rat liver. Mol Cell Biol 34: 1100-1120, 2014

26. Yuan F, Xu Z, Yang M, Wei Q, Zhang Y, Yu J, Zhi Y, Liu Y, Chen $Z$ and Yang J: Overexpressed DNA polymerase iota regulated by JNK/c-Jun contributes to hypermutagenesis in bladder cancer. PLoS One 8: e69317, 2013.

27. Duan F, Yu Y, Guan R, Xu Z, Liang H and Hong L: Vitamin K2 induces mitochondria-related apoptosis in human bladder cancer cells via ROS and JNK/p38 MAPK Signal Pathways. PLoS One 11: e0161886, 2016.

28. Roth B, Jayaratna I, Sundi D, Cheng T, Melquist J, Choi W, Porten S, Nitti G, Navai N, Wszolek M, et al: Employing an orthotopic model to study the role of epithelial-mesenchymal transition in bladder cancer metastasis. Oncotarget 8: 34205-34222, 2017. 
29. Chaffer CL, Brennan JP, Slavin JL, Blick T, Thompson EW and Williams ED: Mesenchymal-to-epithelial transition facilitates bladder cancer metastasis: Role of fibroblast growth factor receptor-2. Cancer Res 66: 11271-11278, 2006.

30. Hulit J, Suyama K, Chung S, Keren R, Agiostratidou G, Shan W, Dong X, Williams TM, Lisanti MP, Knudsen K, et al: N-cadherin signaling potentiates mammary tumor metastasis via enhanced extracellular signal-regulated kinase activation. Cancer Res 67: 3106-3116, 2007.

31. Baek SH, Ko JH, Lee JH, Kim C, Lee H, Nam D, Lee J, Lee SG Yang WM, Um JY, et al: Ginkgolic acid inhibits invasion and migration and TGF- $\beta$-induced EMT of lung cancer cells through PI3K/Akt/mTOR inactivation. J Cell Physiol 232: 346-354, 2017.

32. Vos MC, Hollemans E, Ezendam N, Feijen H, Boll D, Pijlman B, van der Putten H, Klinkhamer P, van Kuppevelt TH, van der Wurff AA, et al: MMP-14 and CD44 in epithelial-tomesenchymal transition (EMT) in ovarian cancer. J Ovarian Res 9: 53, 2016.

33. Zeng Y, Yao X, Chen L, Yan Z, Liu J, Zhang Y, Feng T, Wu J and Liu X: Sphingosine-1-phosphate induced epithelial-mesenchymal transition of hepatocellular carcinoma via an MMP-7/ syndecan-1/ TGF- $\beta$ autocrine loop. Oncotarget 7: 63324-63337, 2016.

34. Wu CL, Ho JY, Chou SC and Yu DS: miR-429 reverses epithelialmesenchymal transition by restoring E-cadherin expression in bladder cancer. Oncotarget 7: 26593-26603, 2016.

35. Wang R, Ke ZF, Wang F, Zhang WH, Wang YF, Li SH and Wang LT: GOLPH3 overexpression is closely correlated with poor prognosis in human non-small cell lung cancer and mediates its metastasis through upregulating MMP-2 and MMP-9. Cell Physiol Biochem 35: 969-982, 2015
36. Song H, Pan D, Sun W, Gu C, Zhang Y, Zhao P, Qi Z and Zhao S: SiRNA directed against annexin II receptor inhibits angiogenesis via suppressing MMP2 and MMP9 expression. Cell Physiol Biochem 35: 875-884, 2015.

37. Cheng HL, Lin CW, Yang JS, Hsieh MJ, Yang SF and Lu KH: Zoledronate blocks geranylgeranylation not farnesylation to suppress human osteosarcoma U2OS cells metastasis by EMT via Rho A activation and FAK-inhibited JNK and p38 pathways. Oncotarget 7: 9742-9758, 2016.

38. Lee YS, Kim SY, Song SJ, Hong HK, Lee Y, Oh BY, Lee WY and Cho YB: Crosstalk between CCL7 and CCR3 promotes metastasis of colon cancer cells via ERK-JNK signaling pathways. Oncotarget 7: 36842-36853, 2016.

39. Ebelt ND, Cantrell MA and Van Den Berg CL: c-Jun N-terminal kinases mediate a wide range of targets in the metastatic cascade. Genes Cancer 4: 378-387, 2013.

40. Ji J, Jia S, Jia Y, Ji K, Hargest R and Jiang WG: WISP-2 in human gastric cancer and its potential metastatic suppressor role in gastric cancer cells mediated by JNK and PLC- $\gamma$ pathways. Br J Cancer 113: 921-933, 2015.

41. Ma W, Gilligan BM, Yuan J and Li T: Current status and perspectives in translational biomarker research for PD-1/PD-L1 immune checkpoint blockade therapy. J Hematol Oncol 9: 47, 2016.

42. Liu B, Song Y and Liu D: Recent development in clinical applications of PD-1 and PD-L1 antibodies for cancer immunotherapy. J Hematol Oncol 10: 174, 2017. 